\title{
Danish Pre-service Teachers' Mathematical and Didactical Knowledge of Operations with Rational Numbers
}

\author{
Zetra Hainul Putra ${ }^{1,2^{*}}$ \\ ${ }^{1}$ Department of Science Education, University of Copenhagen, DENMARK \\ 2 Faculty of Teacher Training and Education, University of Riau, INDONESIA \\ *CORRESPONDENCE: $\square$ zetra.hainul.putra@lecturer.unri.ac.id
}

\begin{abstract}
The aim of this study is to investigate Danish pre-service teachers' (PSTs) mathematical and didactical knowledge of operations with rational numbers. This knowledge is studied through their collaborative activities to certain tasks related to the teaching of operations with rational numbers. An explicit model of the teachers' mathematical and didactical knowledge is designed based on the anthropological theory of the didactic (ATD) and used to analyse five-groups of PSTs' collaborative work. The findings show that the Danish PSTs prefer to use contextual or reallife situations in their teaching, but they encounter various challenges to realise general ideas in the context at hand.
\end{abstract}

Keywords: operations with rational numbers, mathematical and didactical knowledge, anthropological theory of the didactic, collaborative work

\section{INTRODUCTION}

Several studies have showed that many pupils struggle to learn operations with rational numbers (e.g. Gabriel et al., 2013). They tend to apply procedural techniques which are often incorrect such as adding fractions by simply adding the numerators and the denominators. It is also the case in Denmark that onethird of all Danish grade nine pupils could not solve a simple addition task of two fractions at the national exam (Danish Ministry of Education, 2011). This leads to serious problems for them to learn more advanced mathematics, especially basic algebra.

Pupils' difficulties to learn rational numbers are believed to be caused by several factors, and one of them is insufficient teachers' knowledge (Siegler \& Lortie-Forgues, 2017). Ma (1999), for instance, has showed that U.S teachers who merely mastered a procedural technique for the division task of fractions, were unable to construct real-life problems whose solution involves the same computations. In contrast, Chinese teachers performed better. Meanwhile, there is no evidence how Danish teachers deal with pupils' difficulties on rational numbers. This motivates the author to focus on Danish student teachers' knowledge of rational numbers, specifically the arithmetic operations with rational numbers.

The present study investigates pre-service teachers' (PSTs) collective knowledge of operations with rational numbers. It is different from most large-scale studies focusing on teachers' individual knowledge, as measured through written tests (Bradshaw, Izsák, Templi, \& Jacobsen, 2014; Castro-Rodríguez, Pitta-Pantazi, Rico, \& Gómez, 2015; Chinnappan \& Forrester, 2014; Depaepe et al., 2015; Jacobsen \& Izsák, 2015; Sahin, Gökkurt, \& Soylu, 2015; Van Steenbrugge, Lesage, Valcke, \& Desoete, 2014). The teachers' collective knowledge means the knowledge which they could generate and share with colleagues, and which may represent more adequate

Article History: Received 18 December $2018 \bullet$ Revised 15 March $2019 \bullet$ Accepted 6 April 2019

(C) 2019 by the authors; licensee Modestum Ltd., UK. Open Access terms of the Creative Commons Attribution 4.0 International License (http://creativecommons.org/licenses/by/4.0/) apply. The license permits unrestricted use, distribution, and reproduction in any medium, on the condition that users give exact credit to the original author(s) and the source, provide a link to the Creative Commons license, and indicate if they made any changes. 
pictures of the basis of their professional work. Therefore, the design of this study is based on small-scale collaborative work situations. Francisco (2013) showed that "collaborative work provides opportunities for students to critically re-examine how they make claims from facts and also enable them to build on one another's ideas to construct more sophisticated ways of reasoning". One can hypothesize that the same will be the case when two or more teachers discuss a professional task for teachers (which includes both a mathematical and a didactical problem, the latter referring to a teaching problem related to the mathematical problem). This idea was initially developed by Durand-Guerrier, Winsløw and Yoshida (2010) and Winsløw and Durand-Guerrier (2007), who experimented some simple examples of what they call hypothetical teacher task (HTT). Working with an HTT, pairs of teachers or PSTs are given the opportunity to share and link their mathematical and didactical knowledge. Moreover, as a result of the informants working in pairs, one can gain information not just about the techniques they are able to apply to the task, but also how they describe and justify these techniques. More specifically, the present study investigates the following research questions:

RQ1. What mathematical and didactical knowledge do Danish PSTs possess to address challenging situations in the teaching of rational number operations?

RQ2. How do they produce mathematical and didactical knowledge of operations with rational numbers during their collaborative work? What relations do appear between the two components?

In the following sections, I first review some previous studies on teachers' knowledge of operations with rational numbers. Then, I introduce the anthropological theory of the didactic (ATD) as a framework to study Danish PSTs' mathematical and didactical knowledge of operations with rational numbers. The method section presents information about the participants, the design of HTTs, and the data analysis. After that, I present the results from the Danish PSTs' individual and collaborative work on each HTT. Finally, the discussion tries to answer the two research questions related to study teachers' knowledge in the setting of collaborative work.

\section{TEACHERS’ KNOWLEDGE OF OPERATIONS WITH RATIONAL NUMBERS}

Operations with rational numbers provide several challenges for teachers (An, Kulm, \& Wu, 2004; Ball, 1990; Depaepe et al., 2015; Ma, 1999; Newton, 2008; Van Steenbrugge et al., 2014). Many teachers cannot relate standard computational procedures with appropriate rationales for those procedures (e.g. Van Steenbrugge et al, 2014). One reason for this gap is that PSTs have difficulties to recognise a fraction as a single rational number. Another reason is that rational numbers have several common representations, unlike natural numbers (Van Dooren, Lehtinen, \& Verschaffel, 2015). For instance, rational numbers can be represented as fractions, decimals, percentages, or diagrams. Two different representations can be used to serve the same number (Vamvakoussi, Van Dooren, \& Verschaffel, 2012), and each representation comes with different methods or algorithms related to doing operations.

In the case of addition and subtraction of fractions, a prevalent mistake among PSTs is to add and subtract numerators and denominators based on their positions (Newton, 2008). They tend to use this technique especially when the task involves two fractions with different denominators. A common method to investigate teachers' knowledge of adding and subtracting fractions is to ask them to write word problems (Austin, Carbone, \& Web, 2011; Dixon et al., 2014; Kar \& Isik, 2014). Austin et al. (2011), focusing their study on adding fractions, found an issue related to PSTs' inability to recognise that uniform units have to be used. For instance, a PST poses a task such as pupil A has $1 / 2$ of his pizza and pupil B has $3 / 4$ of her pizza, how much pizza do they have together? This word problem looks correct, but the two units (pizzas) may not being the same size and shape. A similar finding is also discussed by Dixon et al. (2014) on subtracting of fractions: when PSTs are asked to pose a word problem, for instance $\frac{a}{b}-\frac{c}{d}$, they tend to write a problem to represent $\frac{a}{b}-\frac{c}{d} \times \frac{a}{b}$. They tend to use an incorrect redefinition of the whole, and the fractions involved in the tasks influence PSTs' performance on writing the word problems.

Previous studies on how teachers deal with multiplication and division of rational numbers also show that teachers may succeed to solve operations of fractions themselves but still be unable to explain the reasons behind the used techniques (Alenazi, 2016; Ball, 1990; Erdem, Gökkurt, Şahin, Başıüyük, \& Soylu, 2015; Ma, 1999; Putra, 2016, 2019; Slattery \& Fitzmaurice, 2014). Ma (1999) found that the U.S. teachers had various misconceptions about the meaning of division by fractions. Confounding division by $\frac{1}{b}$ with division by $b$ and confounding division by $\frac{1}{b}$ with multiplication by $\frac{1}{b}$ were the two common misconceptions when they tried to model the symbolic fraction division task by a word problem. This means that they could not explain the 
meaning of the task based on several interpretations, such as measurement (or quotitive meaning), partitive meaning, and product and factors. Some of PSTs' mistakes on multiplication and division of fractions come from their perception that multiplication "makes bigger" and division "make smaller" (Slattery \& Fitzmaurice, 2014; Tirosh, 2000).

In the present study, I design two teacher tasks based on known misconceptions and difficulties in teaching operations with rational numbers. The first task is about exhibiting teachers' mathematical and didactical ideas to handle pupils' incorrect answers for addition and subtraction of fractions. The second task aims to investigate teachers' mathematical and didactical knowledge for dealing with pupils' difficulties on multiplication and division of decimals (multiplication makes bigger and division make smaller). I design the two tasks with two different representations, fractions and decimals, in order to cover different representations of rational numbers.

\section{THEORETICAL FRAMEWORK: MATHEMATICAL AND DIDACTICAL PRAXEOLOGIES}

Shulman's (1986) seminal work of content knowledge (CK) and pedagogical content knowledge (PCK) led many researchers to focus on teachers' knowledge. In mathematics education, for instance, some researchers try to develop a model to study teachers' CK and PCK, and one of the notable frameworks is mathematical knowledge for teaching (MKT) (Ball Thames, \& Phelps, 2008). This model, like others, mostly focuses on developing large-scale studies of teachers' individual knowledge, but does not provide a detailed method to analyse the connection between teachers' knowledge of theory and practices.

Addressing the need to study teachers' practical and theoretical knowledge as well as individual and collective knowledge, I decided to study teachers' knowledge using the anthropological theory of the didactic (ATD) (Chevallard, 1992, 2006, 2007). I chose ATD because it proposes an epistemological model, that is known as a praxeology, to analyse human activities - including producing, teaching, learning, and conducting mathematical activities. The praxeology is a basic unit into which one can analyse human practice and knowledge into two interrelated components: praxis and logos. The praxis or the practical block consists of a type of tasks $(T)$ and associated techniques ( $\tau$ ) to accomplish each type of tasks. The logos or the theoretical block is related to human thinking and reasoning. Chevallard (2006) argued that no human doing goes unquestioned in the long run, so one needs a technology $(\theta)$ to explain and justify the techniques and a theory $(\Theta)$ to explain and unify several technologies; both belong to the theoretical block. So, a praxeology consists of a 4-tuple $(T, \tau, \theta, \Theta)$ in which all components are intimately linked, and this is a useful tool to analyse teachers' practical and theoretical knowledge together.

The notion of mathematical praxeologies is used to describe teachers' mathematical knowledge of operations with rational numbers (CK). An example of a mathematical type of tasks is to add two rational numbers. The techniques applied to solve that task depend on how the rational numbers are represented. If rational numbers are represented as fractions, a mathematical technique can be a standard procedure of addition of fractions (first rename each fraction with the least common multiple (LCM), then add numerators, and finally simplify the result). Another possible mathematical technique is to change fractions into decimals and then apply the standard procedure for the addition of decimals. An example of technological discourses related to converting fractions to decimals is that changing a fraction into a decimal does not change the value of the number. Notions such as equivalence classes of representations go into the theory to justify that technology.

To study teachers' PCK, ATD proposes the notion of didactic or didactical praxeology (Bosch \& Gascón, 2014; Putra \& Winsløw, 2018, 2019; Rodríguez, Bosch \& Gascón, 2008; Winsløw, Barquero, De Vleeshower, \& Hardy, 2015). A didactical praxeology is defined as a praxeology aiming at making other (mathematical) praxeologies start living in and being shared within human groups (Bosch \& Gascón, 2014). So, the didactical praxeology begins with specific tasks related to help pupils to acquire a mathematical praxeology. A didactical praxeology consists of a type of didactical tasks, didactical techniques, a didactical technology and theory (Rodríguez et al., 2008; Winsløw et al, 2015). An example of a didactic type of tasks is to teach pupils how to add two fractions. The didactical techniques used can be influenced by factors such as teachers' mathematical knowledge or learning experiences. The most common didactical technique is to present directly a common mathematical technique (e.g., an algorithm for adding or subtracting fractions) to the pupils. An example of the technological discourse to justify this didactical technique is the assumption that pupils will learn faster if teachers first present the mathematical technique and then ask pupils to mimic it while solving similar 
mathematical tasks. A theory to justify this didactical technology is direct instructional teaching and learning (Klahr \& Nigam, 2004).

\section{METHODS}

\section{Participants}

The participants were eleven first-year PSTs enrolled in the Bachelor of teacher education programme in a teacher education institution in Denmark. These PSTs volunteered to participate in the study because they desired to learn about rational numbers and were willing to help the researcher to study their learning. They were first-year students who were being prepared to teach pupils from grade 4 to grade 9 . During the data collection, they were taking a course about learning numbers and algebra, and the topic of rational numbers is certainly part of the course. This also motivated the decision to use first-year students as participants. Meanwhile, the main aim of this study is not to evaluate the teacher education programme but to find out how PSTs apply their mathematical knowledge about rational numbers in hypothetical teaching situations.

\section{Design of Hypothetical Teacher Tasks (HTTs)}

The notion of hypothetical teacher tasks (HTTs) was firstly introduced by Winsløw and colleagues (DurandGuerrier, Winsløw, \& Yoshida, 2010; Winsløw \& Durand-Guerrier, 2007) to study and compare PSTs' collective mathematical and didactical knowledge in Denmark, France, and Japan. HTTs are supposed to present mathematical and didactical tasks that can be found in common teaching situations. The teachers have to use various parts of their knowledge to act appropriately. The mathematical contents of the situations are both standard and elementary. For instance, adding two fractions is a common type of tasks that can be found in grade 5 in Danish primary schools (Freil \& Kaas, 2007), and dealing with common pupil misconceptions, such as adding the two fractions based on their positions, is the didactical task that teachers will meet during their teaching experience.

The first HTT focuses on addition and subtraction of fractions (Figure 1). This type of tasks is introduced to Danish pupils in grade 5 and grade 6 (Freil \& Kaas, 2006, 2007). HTT 1 consists of three tasks. The PSTs have to solve individually for the first two tasks, and then use their individual mathematical knowledge to propose didactical praxeologies during the collaborative work in the third task.

You ask sixth grade pupils to compute $\frac{2}{3}+\frac{1}{2}=\cdots$, and $\frac{4}{7}-\frac{1}{3}=\cdots$

a. How do you solve these problems? (to be solved individually within 3 minutes).

You find that many pupils add and subtract fractions in the following way:

$\frac{2}{3}+\frac{1}{2}=\frac{3}{5}$, and $\frac{4}{7}-\frac{1}{3}=\frac{3}{4}$.

b. How do you interpret the pupils' methods? (to be solved individually within 3 minutes).

c. What strategies can you propose to teach these pupils? (discuss in pairs in 5 minutes, use the space below if necessary, and write your ideas to support the discussion).

Figure 1. HTT about addition and subtraction of fractions (Putra, 2018)

The second HTT focuses on multiplication and division of decimals (Figure 2). The Danish pupils start to learn it in grade 6 (Freil \& Kaas, 2006). The task is adapted from the TEDS-M study (Tatto et al., 2008), and the mathematical task is integrated with the didactical task. PSTs are expected to share their mathematical and didactical knowledge to handle pupils' misconception on multiplication and division of decimals simultaneously during their collaborative work. 
As a teacher, you ask pupils to compute the following as homework:

a) $0.25 \times 8=\cdots, b) 8 \div 0.25=\cdots$

At the next meeting in the class, a pupil notices that when he enters $0.25 \times 8$ into a calculator, the answer is smaller than 8 , and when he enters $8 \div 0.25$, the answer is greater than 8 . He is confused with this answer and thinks that the calculator must be broken.

What can you do to help such pupils understand this result? (discuss in pairs in 8 minutes, use the space below if necessary, and write your ideas to support the discussion)

Figure 2. HTT about multiplication and division of decimals (Putra, 2018)

\section{Data Collection and Data Analysis}

The HTTs were originally written in English and subsequently translated into Danish by a master's student who studied didactics of mathematics. Then, a mathematics educator at a University College and a mathematics education researcher at a University reviewed the translated items. After some revisions, the HTTs were tested in January 2016 with the eleven Danish PSTs.

The PSTs mostly worked in pairs, except for one group consisting of three students, so there are five small groups/pairs ${ }^{1}$ of PSTs (coded as $\mathrm{S}_{1}-\mathrm{S}_{5}$ ). Each pair solved the two HTTs one by one, and the researcher and the master's student observed and videotaped their collaborative work. The main focus of PSTs' collaborative work is to discuss the didactical tasks, such as how to handle pupils' misconceptions and difficulties and how to pose adequate didactical praxeologies.

The data from this study consist of PSTs' written answers and video recordings. The transcripts from their collaborative work were done by the master's student. She first transcribed the data into Danish and then translated it into English. Then, the written answers and video transcripts were analysed in terms of mathematical and didactical praxeologies; techniques, technologies, and also possible theories exhibited by the PSTs. The data were analysed using Nvivo 11 software. The mathematical techniques were coded from PSTs' written answers, and the didactical techniques were indicated by PSTs' explanations on how they explained the mathematical techniques to the pupils. The mathematical and didactical technologies were indicated by PSTs' explanations and justifications to the given techniques. For instance, an explanation of why the technique of making a common denominator is needed to solve the mathematical task of adding and subtracting fractions is a kind of mathematical technology, and an explanation of why a teacher needs to represent the mathematical task into a concrete situation is a kind of didactical technology. While, the mathematical theories were indicated by mathematical terminologies mentioned and appeared in the transcripts and the didactical theories may not appear in the discussion, but it can be implied from the didactical technologies given by PSTs. For instance, when a PST gives an explanation to teach pupils using a concrete situation, a possible didactical theory to explain it is such as the constructivism theory (Piaget, 1964). The process of analysing data was done by the author, and passages indicating mathematical and didactical praxeologies were read several times. The passages containing questionable points were discussed with the master's student and one mathematics education researcher who are familiar with the content and context of the study.

\section{FINDINGS}

\section{The Praxeological Analysis of PSTs' Written Answers on Adding and Subtracting Fractions}

The eleven Danish PSTs did not have any difficulty to solve the mathematical task for addition and subtraction of fractions $\left(\mathrm{T}_{\mathrm{a}}\right)$. All of them gave correct answers using the standard technique; change each fraction into a common denominator and then add numerators $\left(\tau_{\mathrm{a} 1}\right)$. Three PSTs showed how they found the common denominator.

\footnotetext{
${ }^{1}$ The term "pair" is used referring to all groups.
} 
The answers to the task of interpreting pupils' answers $\left(\mathrm{T}_{\mathrm{b}}\right)$ indicated that all of them recognised the mistakes underlying the pupils' answers. The pupils just added and subtracted the numerator to the numerator and the denominator to the denominator $\left(\tau_{a 1}\right)^{-}$. They gave two technologies to explain that technique. Ten PSTs assumed that the pupils inappropriately applied properties of natural numbers to the tasks of adding and subtracting two fractions $\left(\theta_{\mathrm{b} 1}\right)$. The second technology is that the pupils just employed the standard procedure for multiplication of two fractions $\left(\theta_{\mathrm{b} 2}\right)$. $\theta_{\mathrm{b} 2}$ is only produced by one PST, $\mathrm{S}_{2 \mathrm{a}}$, who writes: "the pupils have confused the calculation rules for addition and multiplication of fractions, so they operated the numerators and the denominators as the multiplicative rule".

\section{The Praxeological Analysis of PSTs' Collaborative Work on Adding and Subtracting Fractions}

All Danish pairs started the discussion by presenting technological discourses to explain $\tau_{a} 1^{-}$. Besides producing accompanying technologies, four pairs also mentioned that pupils' misunderstanding the concept of fractions is the main cause for their incorrect answers to the task type $\mathrm{T}_{\mathrm{a}}$. The abstract notion of fraction belongs to mathematical theory $(\Theta)$ to justify the technologies. Three pairs provided a detailed explanation what they mean by the concept of fractions; a fraction as a part of a whole, and a fraction as a quotient (Charalambous \& Pitta-Pantazi, 2007). One example comes from the discussion of group 1, $\mathrm{S}_{1 \mathrm{a}}$ and $\mathrm{S}_{1 \mathrm{~b}}$, as follows:

$\mathrm{S}_{1 \mathrm{~b}}:$... It seems like they do not fully understand the concept of fractions. They just think that there are two numbers on both sides of the line, so that they just can add and subtract the numbers.

$\mathrm{S}_{1 \mathrm{a}}$ : They have not understood the value of the numbers, like $\frac{1}{2}$ and $\frac{2}{3}$. You cannot add those before they have the same value.

$\cdots$

$\mathrm{S}_{1 \mathrm{~b}}$ : It is not 1 and 2 . It is a half.

$\mathrm{S}_{1 \mathrm{a}}$ : Yes. It is the same as 0.5 .

The excerpt shows that this pair had the concept of fraction as a number (in the last case, even with an equivalent decimal representation). This means that the pupils need to perceive that a fraction $\frac{a}{b}$ has a value. Mastering this meaning, the pupils will not have any constraint on the size of the fraction, whether the numerator is smaller, equal, or greater than the denominator (Charalambous \& Pitta-Pantazi, 2007).

The Danish pairs continued the discussion to formulate some possible didactical techniques for the didactical task of type $\mathrm{T}_{\mathrm{c}}$. The concern of the discussion is to teach pupils correct mathematical techniques and also to prove ta1-incorrect. A common didactical technique is to visualise both problems into concrete examples $\left(\tau_{c 1}\right)$. All pairs suggested representing the task into a well-known context by the pupils, such as pizzas, but only three groups gave a detailed explanation how they could make use of the context to teach pupils, and almost none of them was really aware of uniform units when proposing a real-world problem. They just mentioned the context and then directly moved to the diagram representations. It was illustrated by a discussion of $\mathrm{S}_{5 \mathrm{a}}$ and $\mathrm{S}_{5 \mathrm{~b}}$ as follows: 7 .

$\mathrm{S}_{5 \mathrm{~b}}$ : I will use concrete examples; the chocolate and the pizza. However, the pizza is not easy to divide into

$\mathrm{S}_{5 \mathrm{a}}$ : Yes. But [the task is] $\frac{2}{3}+\frac{1}{2}$. I will say to them " $\frac{3}{5}$ is smaller than a whole, however we should end up with more than a whole, so your method cannot be right”.

S5b: Yes. I think we should

$\mathrm{S}_{5 \mathrm{a}}$ : Draw pizza (both draw circles and shade $\frac{2}{3}$ and $\frac{1}{2}$ )

$\mathrm{S}_{5 \mathrm{~b}}$ : Then we get relate them - can you remember "learn about pizza" by those Norwegians where they divide pizza? It's good!

$\mathrm{S}_{5 \mathrm{a}}$ : I think that they need to have an understanding of the concept. We could practice rules of fractions with them, although I think they will learn more from the pizza. Afterwards they could help develop the rules of fractions. 
$\mathrm{S}_{5 \mathrm{~b}}$ : And then the other task with subtraction... I think we should explain the same.

$\mathrm{S}_{5 \mathrm{a}}$ : I would do the same. If a guy wants $\frac{1}{3}$ of my pizza.

$\mathrm{S}_{5 \mathrm{~b}}$ : I think I will use some kind of chocolate bar with 7 rows.

$\mathrm{S}_{5 \mathrm{a}}$ : Yes. Then we have 4 rows left.

$\mathrm{S}_{5 \mathrm{~b}}$ : Yes. Then we can have 21 as a division. If you use pizza you need to divide it in 21 slices, which is a lot.

From the excerpt, it can be seen how they chose a context to suggest a didactical technique $\tau_{c 1}$. The decision to choose the context of pizzas or chocolate bars depends on the denominators involved in the tasks. It seems that the pizza representations or diagrams have some limitation to represent fractions with uncommon or bigger denominators. Their preference for teaching pupils using diagrams was supported by their belief that pupils would learn more from that, and grasp the concept of fractions. This argumentation is a kind of technological discourse that was present among other pairs during their discussion. Their previous experiences in a mathematics course where they had watched a video how Norwegians worked with pizzas also affect their didactical praxeologies, but they did not discuss this in detail. In addition, at the beginning of the discussion $\mathrm{S}_{5}$ a provided a technological discourse based on a number sense strategy, using 1 as a benchmark. He used it to argue why the result $\frac{3}{5}$ is incorrect.

Besides suggesting the didactical praxeologies based on the contextual or real-life situations, most pairs proposed some alternative didactical techniques. Two of them were to provide pupils with some common fractions to work with $\left(\tau_{\mathrm{c} 2}\right)$, and to change fractions into decimals and then apply the standard procedure for the decimals $\left(\tau_{c 3}\right)$. Since they just mentioned this without giving any detailed explanation, it was not possible to grasp technology-theoretical discourses underlying those didactical techniques. For instance, $\mathrm{S}_{1 \mathrm{a}}$ said "pupils could try to change [the fractions involved in the addition task] to decimals and then add them and check if [the answer] gives the same result as $\frac{3}{5}$. They probably realize that it is not the same”. Then, S $1 b$ just agreed with it without considering some challenges that pupils could find when they changed fractions into decimals because three fractions involved in the tasks have periodic infinite decimals (e. g. , $\left.\frac{4}{7}=0 . \overline{571428}\right)$.

\section{The Case of Multiplication and Division of Decimals}

The second HTT consists of two mathematical tasks given to the pupils. They belong to the following types:

$\mathrm{T}_{\mathrm{m}}$ : given a positive decimal number $a<1$ and a positive integer $b$, calculate:

$\mathrm{T}_{\mathrm{m} 1}: a \times b=\cdots, 0<a<1$, and $b$ is a positive integer.

$\mathrm{T}_{\mathrm{m} 2}: b \div a=\cdots, 0<a<1$, and $b$ is a positive integer.

The didactical task presented in the HTT is to ask Danish PSTs' ideas to help pupils to understand why the results of the mathematical task $\mathrm{T}_{\mathrm{m}}$ contradict to the pupils' common knowledge of multiplication and division of natural numbers $\left(\mathrm{T}_{\mathrm{d}}\right)$. To answer this didactical task, the pairs proposed several ideas that can be generalised into two didactical praxeologies; didactical praxeologies based on supposedly "intuitive contexts" and didactical praxeologies constructed directly from their mathematical knowledge. I discuss both praxeologies in detail in the following subsections.

\section{Didactical praxeologies based on supposedly "intuitive contexts"}

One of commonalities among five Danish pairs in discussing the second HTT was to want to teach pupils based on real-life situations. They provided several ideas for how to situate the mathematical tasks in intuitive contexts that they assumed to be related to pupils' experience. Some pairs found some challenges, especially on the division task, because they struggled to shift from division with whole numbers to rational numbers. In general, they proposed two didactical techniques that can be described as follows:

$\tau_{d 1}$ : represent the mathematical tasks into contexts that are assumed to be related to what pupils experience in their daily life.

$\tau_{\mathrm{d} 2}$ : use concrete or manipulative objects to support pupils' learning of multiplication and division with rational numbers less than 1.

Five and four pairs discussed the didactical technique $\tau_{\mathrm{d} 1}$ for the multiplication and division task respectively, while the didactical technique $\tau_{\mathrm{d} 2}$ was only discussed by $\mathrm{S}_{1}$ for the multiplication task and $\mathrm{S}_{2}$ for 
the division task but not in detail. They used various contexts, but most of them still considered to begin with a pizza or a cake context to show that 0.25 equals to $\frac{1}{4}$. As an example, $\mathrm{S}_{2 \mathrm{~b}}$ begins the discussion by arguing that they could use a cake or a pizza to show the pupils that $\frac{1}{4}$ corresponds to 0.25 . They successfully apply this context to the multiplication task with decimals, but some of them found it difficult to explain the division task with decimals. For instance, $\mathrm{S}_{1 \mathrm{a}}$ argued "I do not know how to do division in this case. I can calculate it on my pocket calculator and I know how to read the answer on the display".

In term of mathematical praxeologies, four and three pairs tended to construct the contextual problems based on the meaning of multiplication as repeated addition and division as repeated subtraction (quotative division) respectively. For the multiplication task, $0.25 \cdot 8$ was mostly reinterpreted as $8 \cdot 0.25$. For instance, $\mathrm{S}_{4 \mathrm{a}}$ said "here is 25 øre and if you have 8 of these coins how many krones do you then have? ( 1 krone $=100$ øre)". His partners agreed that it was a good example because you can use the repeated addition. It seems that they were really unaware of how to differentiate $0.25 \cdot 8$ from $8 \cdot 0.25$ when modelling the task by a contextual problem. Meanwhile, when posing the didactical techniques $\tau_{d 1}$ based on repeated subtraction, they tended to convert decimals into fractions or natural numbers. For instance, $\mathrm{S}_{5 \mathrm{a}}$ said "in the other case we can say that we have 8 litres of milk, and these should be divided into these 250 [ml]“. This kind of didactical technique will lead the pupils to learn not only the division of rational numbers but also the relation among standard units $\left(1\right.$ litre $=1000 \mathrm{ml}$ ). Alternatively, one group constructed the didactical technique $\tau_{\mathrm{d} 1}$ for the multiplication task based on proportion and for the division task based on the inverse of multiplication (Alenazi, 2016). S $\mathrm{S}_{1 \mathrm{~b}}$ proposed an idea using the example of a quarter of a cake. She said "what do you have with 4 quarters of a cake? You have a whole cake. What if you have 2 cakes? Then you have 8 quarters". For the division task, it was illustrated by the discussion of PSTs from group 3 as follows:

$\mathrm{S}_{3 a}$ : However, I think it is a good idea to say that as before "we are 4 people and I get 8 , how much do we then have together?

$\mathrm{S}_{3 \mathrm{~b}}$ : I have been told always to make a story about the case. I got 100 krone or something like that, and it is told that it was my share of the profit. We are 8 people sharing the profit. How great was the profit?

$\mathrm{S}_{3 a}:$ Yes.

$\mathrm{S}_{3 \mathrm{~b}}$ : It must have been $12.5[\%]$, so 100 divided by 0.125 . This gives in total 800 .

The excerpt shows that they tried to construct a contextual problem that was indirectly recognised as the decimal division task. The pupils may solve this problem using the technique for multiplication instead of the division. In fact, a teacher has an important role to make the pupils aware that there is a link between multiplication and division, namely, division is the inverse of multiplication.

In the discussion, all pairs provided justification why they would teach the pupils based on the real-life situations. They considered that the multiplication and division tasks given to the pupils were too abstract, and those tasks were needed to be visualised.

$\mathrm{S}_{2 \mathrm{~b}}$ : That is what I had in mind. I will try to visualise it. Do they say which grade is it?

$\mathrm{S}_{2 \mathrm{a}}$ : No. I don't think so.

$\mathrm{S}_{2 \mathrm{~b}}$ : No, but even in the higher grades, they find it difficult to see that it is just a number. I like to visualise it.

$\mathrm{S}_{2 \mathrm{a}}$ : Absolutely! We have to show them that 0.25 is the same as $\frac{1}{4}$.

In general, this justification can be formed as a following didactical technology:

$\theta_{\mathrm{d} 1}$ : the multiplication and division tasks need to be visualised to help pupils understand the value of numbers better, and the result of the operations.

None of Danish PSTs directly mentioned any didactical theory to justify this didactical technology, but the general virtue of teaching mathematics beginning from contextual problems can be seen as an informal didactical theory $\left(\Theta_{\mathrm{d} 1}\right)$. This is in line with the Piaget's theory of cognitive development, including that the pupils in the age of 7 to 11 years are still in the concrete operational stage (Piaget, 1964). But this is not referred explicitly by the PSTs. 


\section{Didactical praxeologies constructed directly from PSTs' mathematical praxeologies}

Four pairs also discussed some possible didactical techniques that were built directly from their mathematical knowledge. This is mainly because the whole number and the decimal involved in the multiplication and division tasks were intuitively recognised by them. In general, the didactical techniques suggested can be described as follows:

$\tau_{\mathrm{d} 3}$ : reformulate mathematical sentences for the multiplication or division tasks that can be easily understood by the pupils.

$\tau_{\mathrm{d} 4}$ : use pupils' knowledge of operations with natural numbers to explain operations with rational numbers (from proportion to function, see example given by $\mathrm{S}_{4 \mathrm{c}}$ below).

$\tau_{\mathrm{d} 5}$ : convert decimals to fractions and then teach the standard algorithm for multiplication and division of fractions.

$\tau_{\mathrm{d} 6}$ : explain the relation between multiplication and division of two rational numbers (if $a \times b=c$, then $c \div b=a$ or $c \div a=b$ )

The didactical technique $\tau_{\mathrm{d}} 3$ was discussed by $\mathrm{S}_{1}$ and $\mathrm{S}_{3}$ in relation to the multiplication task, and by $\mathrm{S}_{2}$ in relation to the division task. One example of $\tau_{\mathrm{d} 3}$ related to the multiplication task was to change 0.25 into $25 \%$. The multiplication task given to the pupils was to take $25 \%$ of 8 . A mathematical theory underlying this didactical technique is the operator interpretation of rational numbers (Charalambous \& Pitta-Pantazi, 2007).

Two pairs discussed the didactical technique $\tau_{\mathrm{d} 4}$ especially for the multiplication task. Actually, there was pros and cons when they proposed this didactical technique because they still considered that it was too abstract and not really related to the contextual situation. As an example, it was illustrated by a discussion from $\mathrm{S}_{4}$.

$\mathrm{S}_{4 \mathrm{c}}$ : I think we can make a number table.

then he draws a table as follows:

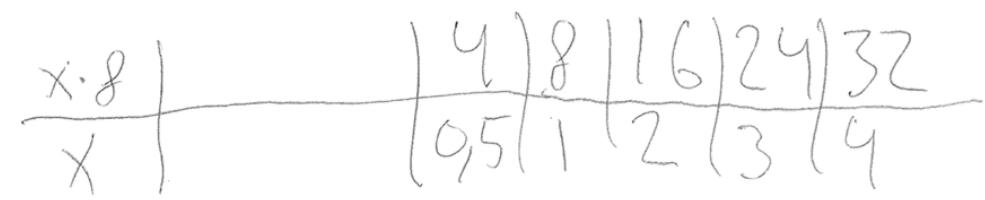

$\mathrm{S}_{4 \mathrm{c}}$ : If we ask them to place numbers like 8,24 , and 32 in a row, then they can see that it has to be greater. Then we could make them write numbers in the row below. It could be a half and then we get 4 . Afterwards they could make a graph and see if they can see any relations between the numbers and try to explain why division by decimals gives a greater number.

$\mathrm{S}_{4 \mathrm{a}}$ : I still think that it is too abstract for them. They need to look at pizzas and work with small things.

$\mathrm{S}_{4 \mathrm{~b}}$ : I think they have misunderstood that. I remember that multiplication always gives a greater number and this is the rule they struggle with. They just think that all multiplication gives a greater number. That is the problem.

$\mathrm{S}_{4 \mathrm{c}}$ : Yes, but not always. When you multiply by something smaller than 1 you get something smaller.

$\mathrm{S}_{4 a}$ : That is the same problem as before (addition and subtraction tasks), where they did not understand the numerator and the denominator in a fraction. The rest is just numeracy. I think it is still too abstract for them.

$\mathrm{S}_{4 \mathrm{c}}$ : I can see that.

From the excerpt, it can be seen that $\mathrm{S}_{4 \mathrm{c}}$ provided the didactical technique $\tau_{\mathrm{d} 4}$ built upon the concept of relation and function between factors and products. His mathematical idea was to support the pupils to recognise that the change of factors will affect the products. Letting the pupils draw a graph might put them into a challenge and learn more advanced mathematics, including early algebra and linear functions such as $f(x)=8 x$. However, his partners considered this didactical technique as too abstract because it was not so in line with the common didactical theory $\left(\Theta_{\mathrm{d} 1}\right)$.

The didactical technique $\tau_{\mathrm{d} 5}$ was only discussed by one pair, $\mathrm{S}_{2}$. They considered this as an alternative didactical technique to teach pupils. They believed that the pupils could understand this didactical technique 
if they got the meaning of the numerators and the denominators. This was achieved through visualising the tasks into something that the pupils recognise e.g., a pizza $\left(\theta_{\mathrm{d} 1}\right)$.

Since the task was integrated into multiplication and division of decimals, two groups simultaneously discussed the relationship between multiplication and division $\left(\tau_{d} 6\right)$. One example from the discussion of group 4 as follows:

$\mathrm{S}_{4 \mathrm{a}}$ : What happens if we take 2 times 3 , this is 6 , divided by 3 gives 2 . (write: $2 \times 3=6,6 \div 3=2$, and puts a ring around the number 2). What happens if we multiply 0.25 by 8 , That is 2 . And if we divide 2 by 8 (writes: $0.25 \times 8=2$ and $2 \div 8=0.25$ ).

$\mathrm{S}_{4 \mathrm{c}}$ : Can you not choose to make the division the other way around?

$\mathrm{S}_{4 \mathrm{a}}$ : Yes. We can do that. 8 multiplied by 0.25 equals to 2 . And 2 divided by 0.25 equals to 8 . (writes: $8 \times$ $0.25=2$ and $2 \div 0.25=8$ ). It is the same journey.

$\mathrm{S}_{4 a}$ started presenting an example of multiplication of two positive integers, and then he moved to the example of multiplication of a positive integer by a decimal. He tried to show how multiplication and division are linked each other, and it can be a potential didactical technique to explain the inverse relationship of multiplication and division of rational numbers. Meanwhile, a didactical technology mentioned by this group to justify the didactical technique $\tau_{\mathrm{d} 6}$ was that the pupils had to understand how to multiply by rational numbers before learning the division tasks with rational numbers $\left(\theta_{\mathrm{d} 2}\right)$. This means that learning the division with rational numbers should link to the previous pupils' praxeologies on multiplication $\left(\Theta_{\mathrm{d} 2}\right)$. This theoretical idea is further substantiated by the discussion of concrete didactical techniques.

On the other hand, PSTs from group 1 who tried to employ the didactical technique td6 got difficulty to differentiate between dividing by $\frac{1}{4}$ with dividing by 4 . For instance, after realising the relation between multiplication and division and trying to explain the division task, $\mathrm{S}_{1 \mathrm{a}}$ said "here (referring to the division task) we multiply by $\frac{1}{4}$, No, we divide...I can not explain it". So, what they had experienced was similar to the case of the U.S teachers in Ma's study (1999).

During the discussion, three pairs mentioned that the pupils have to understand that multiplying a natural number with something less than 1 gives a result smaller than that natural number, and one pair also used an opposite argument that dividing a natural number with something less than 1 gives a result bigger than that natural number. This corresponds to a general mathematical theory about multiplication and division with rational numbers that can be stated as follows:

$\Theta_{\mathrm{m}}$ : if $0<a<1$ and $b$ is a natural number, then $a \times b<b$ and $b \div a>b$.

In fact, one can say that these pairs have an adequate mathematical theory that can be used to justify their mathematical technologies.

\section{DISCUSSION AND CONCLUDING REMARKS}

This study examined two research questions. RQ1 concerns Danish PSTs' mathematical and didactical knowledge which they can develop to address challenging situations in the teaching of rational number operations. This knowledge is studied in term of techniques and technological-theoretical discourse. RQ2 concerns how the Danish PSTs produce mathematical and didactical knowledge through collaborative work, and what the relations are between the two components. This was mostly addressed in the context of the second HTT about multiplication and division of decimals, where it turns out to be more challenging for the Danish pairs to propose satisfactory didactical praxeologies.

Regarding RQ1, the results from this study confirm that the Danish PSTs prefer to build didactical praxeologies based on real-life situations. They tend to explain the meaning underlying the mathematical operations involved in the HTTs based on "pizza representations" of rational numbers, and this context functions well for the first HTT, but not for the second HTT. In fact, pizza representations mainly apply to small rational numbers, especially in the interval [0,1], as it is based on the meaning of a fraction as a part of a whole. That is only one among five informal models of rational numbers (Charalambous \& Pitta-Pantazi, 2007), and instructing pupils based on this model will not be sufficient to build more complete semantics of rational numbers (Lamon, 2012). When the PSTs proposed didactical praxeologies for the multiplication and division tasks based on contextual situations, they mostly interpreted the mathematical meaning of the tasks in terms of repeated addition and subtraction, respectively. But some of them are unsecure whether the 
contextual problems suggested are consistent with the given mathematical task, such as $0.25 \times 8$. Misinterpreting the operations of rational numbers into unappropriated contextual problems will blur the meaning of the operations (An et al., 2004). Meanwhile, the most common technological discourse relates to PSTs' belief that concrete representations, such as pizzas, chocolates, etc., are the best aid to teach operations with rational numbers. One possible reason underlying this technological discourse is their learning experiences either as pupils at schools or as student-teachers at the university college. The latter included, for some of them, a video of Norwegian pupils' work with pizza representations, used in the didactics of numbers and algebra. Another reason could be a general pedagogical ideology that "mathematics in real-life" solves all problems for pupils.

Answering RQ2, the Danish pairs struggle to produce appropriate didactical praxeologies, especially as they work on the second HTT. They first consider proposing didactical techniques based on real-life situations, and these techniques relate to their mathematical knowledge, mostly based on a model of multiplication as repeated addition, and division as repeated subtraction. But, some of the PSTs mention that they could not find an appropriate didactical technique to explain the division task. This is caused by the state of their mathematical praxeologies, especially the technological-theoretical discourse related to the justification and details of the standard techniques. PSTs' understanding the meaning of a fraction as a part of whole leads them to some difficulties to explain the tasks on HTT 2. Some of them did not realise other interpretations for those task such measurement (or quotitive meaning), partitive meaning, and product and factors (Alenazi, 2016; Ball, 1990; Ma, 1999; Putra, 2016, 2019; Slattery \& Fitzmaurice, 2014). Some potential didactical techniques such as $\tau_{\mathrm{d} 4}$, constructed directly from their mathematical knowledge, tend to be neglected because they consider that it is too abstract for the pupils. This finding is in accordance with what has been found by Winsløw and Durand-Guerrier (2007) that "the Danish PSTs pay considerably more attention in their discussions to the pedagogical aspects of the situation. They primarily search for applied or concrete examples and illustrations".

To sum up, this study reveals a gap between Danish PsTs' mathematical and didactical knowledge to teach operations with rational numbers. Their tendency to associate mathematical tasks with real-life problems sometimes does not result in appropriate didactical techniques for teaching operations with rational numbers. An insufficient mathematical technological-theoretical discourse for the technique associated with the operations is one of the main factors of their difficulties. At the same time, it must be admitted that this study has some limitations. The first one is related to the small sample of Danish PSTs participating in this study. There were only eleven first-year students, all from the same teacher education institution in Denmark. So, the data from this study cannot be taken as representative for all Danish PSTs. Secondly, the HTTs only focused on two specific types of tasks on operations with rational numbers. Further research should address these limitations by extending the number of participants from different years of study and several institutions, and by providing a wider range of mathematical and didactical tasks types, that may be leading them to produce broader mathematical and didactical praxeologies. In relation to the methodology experimented here, the collaborative setting leads PSTs to discuss their mathematical and didactical praxeologies spontaneously. This can help identify what mathematical knowledge the PSTs have individually, and how they use and negotiate this knowledge to build didactical techniques for teaching rational numbers.

\section{ACKNOWLEDGEMENT}

The author thanks the Ministry of Research, Technology, and Higher Education of the Republic of Indonesia for funding this research under the grant no.102.7/E4.4/2015.

\section{Disclosure statement}

No potential conflict of interest was reported by the authors.

\section{Notes on contributors}

Zetra Hainul Putra - Department of Science Education, University of Copenhagen, Denmark and Faculty of Teacher Training and Education, University of Riau, Indonesia. 


\section{REFERENCES}

Alenazi, A. (2016). Examining middle school pre-service teachers' knowledge of fraction division interpretations. International Journal of Mathematical Education in Science and Technology, 47(5), 696-716. https://doi.org/10.1080/0020739X.2015.1083127

An, S., Kulm, G., \& Wu, Z. (2004). The pedagogical content knowledge of middle school, mathematics teachers in China and the US. Journal of Mathematics Teacher Education, 7(2), 145-172. https://doi.org/10.1023/b:jmte.0000021943.35739.1c

Austin, P., Carbone, R. E., \& Webb, P. (2011). Prospective primary school Teachers' attempts to pose acceptable word problems on the addition of fractions: Some insights from South Africa and the United States of America. African Journal of Research in Mathematics, Science and Technology Education, 15(2), 168-178. https://doi.org/10.1080/10288457.2011.10740710

Ball, D. L. (1990). The mathematical understandings that prospective teachers bring to teacher education. The elementary school journal, 90(4), 449-466. https://doi.org/10.1086/461626

Ball, D. L., Thames, M. H., \& Phelps, G. (2008). Content knowledge for teaching: What makes it special? Journal of Teacher Education, 59(5), 389-407. https://oi.org/10.1177/0022487108324554

Bosch, M. \& Gascón, J. (2014). Introduction to the anthropological theory of the didactic (ATD). In A. BiknerAhsbahs \& S. Prediger (Eds.), Networking of Theories as a Research Practice in Mathematics Education (pp. 67-83). Switzerland: Springer International Publishing. https://doi.org/10.1007/978-3-319-0538995

Bradshaw, L., Izsák, A., Templin, J., \& Jacobson, E. (2014). Diagnosing teachers' understandings of rational numbers: Building a multidimensional test within the diagnostic classification framework. Educational Measurement: Issues and Practice, 33(1), 2-14. https://doi.org/10.1111/emip.12020

Castro-Rodríguez, E., Pitta-Pantazi, D., Rico, L., \& Gómez, P. (2016). Prospective teachers' understanding of the multiplicative part-whole relationship of fraction. Educational Studies in Mathematics, 92(1), 129146. https://doi.org/10.1007/s10649-015-9673-4

Charalambous, C. Y., \& Pitta-Pantazi, D. (2007). Drawing on a theoretical model to study students' understandings of fractions. Educational studies in mathematics, 64(3), 293-316. https://doi.org/10.1007/s10649-006-9036-2

Chevallard, Y. (1992). Fundamental concepts in didactics: perspectives provided by an anthropological approach. In R. Douady \& A. Mercier (Eds.), Research in Didactique of Mathematics (pp. 131-167). Grenoble: La Pensée sauvage.

Chevallard, Y. (2006). Steps towards a new epistemology in mathematics education. In M. Bosch (Eds.), Proceedings of the IV Congress of the European Society for Research in Mathematics Education (pp. 2130). Grenoble: La Pensée Sauvage.

Chevallard, Y. (2007). Readjusting didactics to a changing epistemology. European Educational Research Journal, 6(2), 131 - 134. https://doi.org/10.2304/eerj.2007.6.2.131

Danish Ministry of Education. (2011). Moderne matematiske fardigheder fra skolestart til studiestart [Modern mathematics skills from school start to study start]. Retrieved from http://www2.mat.dtu.dk/people/S.Markvorsen/DISPLAY/ABOUT_MATH1_PROOPG/Faerdigrapport_ Dec_16.pdf

Depaepe, F., Torbeyns, J., Vermeersch, N., Janssens, D., Janssen, R., Kelchtermans, G., ... \& Van Dooren, W. (2015). Teachers' content and pedagogical content knowledge on rational numbers: A comparison of prospective elementary and lower secondary school teachers. Teaching and Teacher Education, 47, 8292. https://doi.org/10.1016/j.tate.2014.12.009

Dixon, J. K., Andreasen, J. B., Avila, C. L., Bawatneh, Z., Deichert, D. L., Howse, T. D., \& Turner, M. S. (2014). Redefining the whole: Common errors in elementary preservice teachers' self-authored word problems for fraction subtraction. Investigations in Mathematics Learning, 7(1), 1-22. https://doi.org/10.1080/24727466.2014.11790336

Durand-Guerrier, V., Winsløw, C. \& Yoshida, H. (2010). A model of mathematics teacher knowledge and a comparative study in Denmark, France and Japan. Annales de didactique et des sciences cognitives, 15, 147-172. 
Erdem, E., Gökkurt, B., Şahin, Ö., Başıüyük, K., \& Soylu, Y. (2015). Examining prospective middle school mathematics teachers' modelling skills of multiplication and division in fractions. Croatian Journal of Education, 17(1), 11-36. https://oi.org/10.15516/cje.v17i1.830

Francisco, J. M. (2013). Learning in collaborative settings: Students building on each other's ideas to promote their mathematical understanding. Educational Studies in Mathematics, 82(3), 417-438. https://doi.org/10.1007/s10649-012-9437-3

Freil, O, \& Kaas, T. (2006). Kolorit matematik for sjette klasse-grundbog [Kolorit mathematics for the sixth grade-basics]. København: Gyldendalske Boghandel, Nordisk Forlag A/S.

Freil, O, \& Kaas, T. (2007). Kolorit matematik for femte klasse-grundbog (2. Oplag) [Kolorit mathematics for the fifth grade-basics $2^{\text {nd }}$ edition]. København: Gyldendalske Boghandel, Nordisk Forlag A/S.

Gabriel, F. C., Coché, F., Szucs, D., Carette, V., Rey, B., \& Content, A. (2013). A componential view of children's difficulties in learning fractions. Frontiers in Psychology, 4, 715. https://doi.org/10.3389/fpsyg.2013.00715

Jacobson, E., \& Izsák, A. (2015). Knowledge and motivation as mediators in mathematics teaching practice: the case of drawn models for fraction arithmetic. Journal of Mathematics Teacher Education, 18(5), 467-488. https://doi.org/10.1007/s10857-015-9320-0

Kar, T., \& Isik, C. (2014). Analysis of problems posed by pre-service primary teachers about adding fractions in terms of semantic structures. International Electronic Journal of Mathematics Education, 9(2), 135146.

Klahr, D., \& Nigam, M. (2004). The equivalence of learning paths in early science instruction: Effects of direct instruction and discovery learning. Psychological Science, 15(10), 661-667. https://doi.org/10.1111/j.0956-7976.2004.00737.x

Lamon, S. J. (2012). Teaching fractions and ratios for understanding: Essential content knowledge and instructional strategies for teachers (3rd Ed.). Mahwah, NJ: Lawrence Erlbaum Associates. https://doi.org/10.4324/9780203803165

Ma, L. (1999). Knowing and Teaching Elementary Mathematics: Teachers' understanding of fundamental mathematics in China and the United State. New Jersey: LEA. https://doi.org/10.4324/9781410602589

Newton, K. J. (2008). An extensive analysis of pre-service elementary teachers: Knowledge of fractions. American Educational Research Journal, $\quad 45(4), \quad 1080 \quad$ - 1110. https://doi.org/10.3102/0002831208320851

Piaget, J. (1964). Part I: Cognitive development in children: Piaget development and learning. Journal of research in science teaching, 2(3), 176-186. https://doi.org/10.1002/tea.3660020306

Putra, Z. H. (2016). Pengetahuan mahasiswa pendidikan guru sekolah dasar dalam merepresentasikan operasi pecahan dengan model persegi panjang [Pre-service elementary teachers' knowledge on representing the fraction operations with rectangle models]. Jurnal Elemen 2(1): 1 - 13. Jurnal Elemen. https://doi.org/10.29408/jel.v2i1.174

Putra, Z. H. (2018). A comparative study of Danish and Indonesian pre-service teachers' knowledge of rational numbers (PhD thesis). University of Copenhagen, Denmark.

Putra, Z. H. (2019). Elementary teachers' knowledge on fraction multiplication: An anthropological theory of the didactic approach. Journal of Teaching and Learning in Elementary Education,2(1), 47-52. https://doi.org/10.33578/jtlee.v2i1.6964

Putra, Z. H., \& Winsløw, C. (2018). Teachers' collective knowledge: the case of equivalent fractions. In R. Johar et al. (Eds.), Proceeding of the $6^{\text {th }}$ South East Asia Design Research International Conference (6 ${ }^{\text {th }}$ SEADR IC) (vol. 1088, pp. 1-6), Journal of Physics: Conference Series. https://doi.org/10.1088/17426596/1088/1/012003

Putra, Z. H., \& Winsløw, C. (2019). Prospective teachers' knowledge of comparing decimals. International on Emerging Mathematics Education, 3(1), 57-68. http://dx.doi.org/10.12928/ijeme.v3i1.11314

Rodríguez, E., Bosch, M., \& Gascón, J. (2008). A networking method to compare theories: metacognition in problem solving reformulated within the Anthropological Theory of the Didactic. ZDM, 40(2), 287-301. https://doi.org/10.1007/s11858-008-0094-Z

Şahin, Ö., Gökkurt, B., \& Soylu, Y. (2016). Examining prospective mathematics teachers' pedagogical content knowledge on fractions in terms of students' mistakes. International Journal of Mathematical Education in Science and Technology, 47(4), 531-551. https://doi.org/10.1080/0020739x.2015.1092178 
Shulman, L. S. (1986). Those who understand: Knowledge growth in teaching. Educational researcher, 15(2), 4-14. https://doi.org/10.3102/0013189x015002004

Siegler, R. S., \& Lortie-Forgues, H. (2017). Hard Lessons: Why Rational Number Arithmetic Is So Difficult for So Many People. Current Directions in Psychological Science, 26(4), 346-351. https://doi.org/10.1177/0963721417700129

Slattery, J., \& Fitzmaurice, O. (2014). 'Ours is not to reason why, just invert and multiply': an insight into Irish prospective secondary teachers' conceptual understanding of the division of fractions. Irish Educational Studies, 33(4), 467-488. https://doi.org/10.1080/03323315.2014.982346

Tatto, M. T., Schwille, J., Senk, S. L., Ingvarso, L., Peck, R., \& Rowley, G. (2008). Teacher education and development study in Mathematics (TEDS-M): Policy, practice, and readiness to teach primary and secondary mathematics conceptual framework. East Lansing, MI: Teacher Education and Development International Study Center, College of Education, Michigan State University.

Tirosh, D. (2000). Enhancing prospective teachers' knowledge of children's conceptions: The case of division of fractions. Journal for Research in Mathematics Education, 5-25. https://doi.org/10.2307/749817

Vamvakoussi, X., Van Dooren, W., \& Verschaffel, L. (2012). Naturally biased? In search for reaction time evidence for a natural number bias in adults. The Journal of Mathematical Behaviour, 31(3), 344-355. https://doi.org/10.1016/j.jmathb.2012.02.001

Van Dooren, W., Lehtinen, E., \& Verschaffel, L. (2015). Unraveling the gap between natural and rational numbers. Learning and Instruction, 37, 1-4. https://doi.org/10.1016/j.learninstruc.2015.01.001

Van Steenbrugge, H., Lesage, E., Valcke, M., \& Desoete, A. (2014). Preservice elementary school teachers' knowledge of fractions: a mirror of students' knowledge? Journal of Curriculum Studies, 46(1), 138161. https://doi.org/10.1080/00220272.2013.839003

Winsløw, C., Barquero, B., De Vleeshower, M., \& Hardy, N. (2015). An institutional approach to university mathematics education: from dual vector spaces to questioning the world. Research in Mathematics Education, 16(2), 95-111. https://doi.org/10.1080/14794802.2014.918345

Winsløw, C., \& Durand-Guerrier, V. (2007). Education of lower secondary mathematics teachers in Denmark and France, Nordic Studies in Mathematics Education 12(2), 5-32. 